\title{
NUMERICAL ANALYSIS OF LIQUID FRACTION AND HEAT FLUX IN THE SOLIDIFICATION PROCESS OF ERYTHRITOL IN SPHERES
}

\begin{abstract}
J. H. N. Ehms,
F. A. Bodnar,

I. D. R. dos Santos, and R. D. C. Oliveski

Universidade do Vale do Rio dos Sinos -

UNISINOS

Programa de Pós -Graduação em Engenharia

Mecânica

Av. Unisinos, 950

São Leopoldo, Rio Grande do Sul, Brasil jhehms@gmail.com

Received: May 25, 2017

Revised: June 19, 2017

Accepted: July 17, 2017

ABSTRACT

The demand for renewable energy resources and the need for the development of components which increase how it collects, transforms, stores and distributes this energy, emphasizes the importance of improving current technological systems to meet these demands. Phase change materials (PCM) offer great potential in this area. as they can increase energy efficiency in thermal systems as well as save energy by storing solar energy or waste heat from industrial processes, which is made possible by the high amount of energy stored per mass and volume unit, with low temperature variation. Therefore, it is of high importance that the suggested mathematical and numerical models are capable of analyzing its energy performance. The present work uses a mathematical and numerical model of Computational Fluid Dynamics (CFD), capable of reproducing the solidification process of erythritol in spheres of $10,20,30$ and $40 \mathrm{~mm}$ diameters, with temperature differences of $10,15,20,25,30$ and $40 \mathrm{~K}$ between the sphere wall and the phase change temperature of the material. The problem is considered twodimensional and transient. The model consists of mass, energy, momentum and volume fraction equations. The mathematical and numerical model is validated with experimental results from the literature, presenting good agreement between them. After space and time discretization tests, we analyze liquid fraction over time and heat flux at the sphere wall. The results show that liquid fraction suffers a strong reduction in the beginning of the solidification process due to the high heat flux in the early stages. As the solid layer near the wall increases, it causes an increase in thermal resistance, causing a significant reduction in heat flux.

Keywords: phase change materials (PCM), solidification, thermal energy storage, erythritol
\end{abstract}

\section{NOMENCLATURE}

$C \quad$ mushy zone constant, $\mathrm{kg} / \mathrm{m}^{3} \mathrm{~s}$

$C_{p} \quad$ specific heat, $\mathrm{J} / \mathrm{kg} \mathrm{K}$

$D$ diameter, $\mathrm{m}$

$d t \quad$ time step, $\mathrm{s}$

$g$ gravity acceleration, $\mathrm{m} / \mathrm{s}^{2}$

$h \quad$ enthalpy, $\mathrm{J} / \mathrm{kg}$

$k$ thermal conductivity, $\mathrm{W} / \mathrm{m} \mathrm{K}$

$L \quad$ latent heat, $\mathrm{J} / \mathrm{kg}$

$p$ pressure, $\mathrm{Pa}$

q" $\quad$ heat flux, $\mathrm{W} / \mathrm{m}^{2}$

$S$ momentum source term, $\mathrm{Pa} / \mathrm{m}$

$t$ time, $\mathrm{s}$

$T$ temperature, $\mathrm{K}$

$\vec{V} \quad$ velocity vector, $\mathrm{m} / \mathrm{s}$

\section{Greek symbols}

$\alpha_{n} \quad$ volume fraction in computational cell

$b$ liquid fraction

$\Delta \quad$ difference

$\varepsilon \quad$ numerical constant, 0,001

$\mu \quad$ dynamic viscosity, $\mathrm{kg} / \mathrm{m} \mathrm{s}$

$\rho \quad$ density, $\mathrm{kg} / \mathrm{m}^{3}$

\section{Subscripts \\ l liquid \\ la latent \\ ref reference \\ $s \quad$ solid \\ se sensible}

\section{INTRODUCTION}

The growing demand for renewable energy resources, driven by the necessity to reduce emissions that influence climate changes, as well as profit made from the renewable resources industry, stimulates the development of technological apparatuses that can analyze the performance of thermal components and systems. Phase change materials (PCM) (used in components for thermal energy storage), studied with CFD is of great value, since they are both used to attenuate energy peaks and to supply energy during low availability periods, as of solar energy, for example.

In this scenario, the utilization of proper computational models becomes an important analysis tool for thermal and energy system efficiency, where physical phenomena in these systems can be observed and evaluated. Therefore, it is possible to 
analyze the physical aspects of the components that influence the performance of thermal systems, proposing improvements and solutions of eventual problems.

PCM store latent heat, where the main feature is to store great amounts of energy per mass unit within a small temperature range (Sharma et al., 2009). This makes these materials suitable for many applications, such as energy storage in solar thermal energy, refrigeration, food conservation, medical applications, and thermal energy storage in concentrating solar power plants and waste heat recovery in industrial processes. Thus, PCM demonstrate great potential, mainly from the point of view of energy efficiency, reflected in economic aspects.

The choice of a PCM for a given application is defined mainly by its phase change temperature, the range of most currently studied PCM are between the temperatures of 0 and $60^{\circ} \mathrm{C}$ (Agyenim et al., 2010a). In this range, heating, air conditioning and solar thermal energy are the main applications. However, the amount of studies available reduces considerably for PCM with higher phase change temperature, where the material can be suitable for industrial processes.

Numerical studies of PCM RT25 melting in two-dimensional and three-dimensional rectangular geometry, with different aspect ratios and thermal conditions were completed by Shatikian et at. (2005). For each aspect ratio analyzed $\Delta T=6,12,18$ and $24 \mathrm{~K}, \Delta T$ being the difference between the wall temperature and the PCM phase change temperature. Oliveski and Del Col (2014) also studied numerically the melting process in the same geometry, but with erythritol, with $\Delta T=10,15$ and $20 \mathrm{~K}$. Bohrael et al. (2015) also presented a numerical study of erythritol melting in a two-dimensional rectangular geometry, analyzing the influence of its height in the process, under the same thermal condition.

Schmueli et al. (2010) analyzed different configurations of the numerical method and compared them to experimental results, using the PCM RT27 in a vertical cylindrical cavity. Estrázulas (2015) studied numerically the same geometry with different PCM: RT4, RT35, RT35HC, RT55 and RT82. For each material the values $\Delta T=10,20$ and $30 \mathrm{~K}$ were applied.

Agyenim et al. (2010b) performed experimental tests of two tubular arrangements in the melting process of erythritol: one arrangement is composed of two concentric tubes with PCM in the annular region and working fluid in the inner tube; the other is composed of four smaller inner tubes with working fluid inside a bigger tube filled with PCM. The parameters analyzed were the temperatures in axial, radial and angular directions, as well as the influence of the working fluid flow rate and temperature.

Numerical study of RT27 solidification inside a vertical two-dimensional cylinder was presented by
Dubovsky et al. (2008), analyzing the aspect ratio, the portion of the geometry filled with PCM and the thermal condition. Assis et al. (2009) also studied the solidification of RT27, but in spheres. The diameter of $40 \mathrm{~mm}$ was tested experimentally in order to validate the numerical model that was used to analyze different diameters and thermal conditions. The same geometry was studied by Borahel et al. (2015), which analyze numerically the influence of the wall temperature in the solidification of erythritol in twodimensional spherical geometry.

This work's main objective is to present a numerical computational model, capable of allowing the study of the solidification process of erythritol inside a sphere, in a two-dimensional transient model and analyzing its behavior over time according to the aspects of liquid fraction $(\beta)$ and heat flux $(q$ ').

\section{NUMERICAL MODEL}

In the present work, numerical simulation with CFD is used. Within the software, ANSYS ICEMCFD 16.1 was used to create the geometry and mesh; ANSYS Fluent 16.1 to run the simulations and execute part of the post-processing and ANSYS CFD-Post 16.1 to complete the post-processing. In this section the physical and mathematical models, boundary conditions and other configurations used in the simulations, as well as analysis of temporal and spatial discretization tests are presented.

The geometry analyzed in the present work is spherical, as shown in Figure 1, and is filled with 98.5\% of PCM and the remaining part is filled with air, that flows across the opening in the upper part, in order to keep constant pressure inside the sphere during the solidification process.

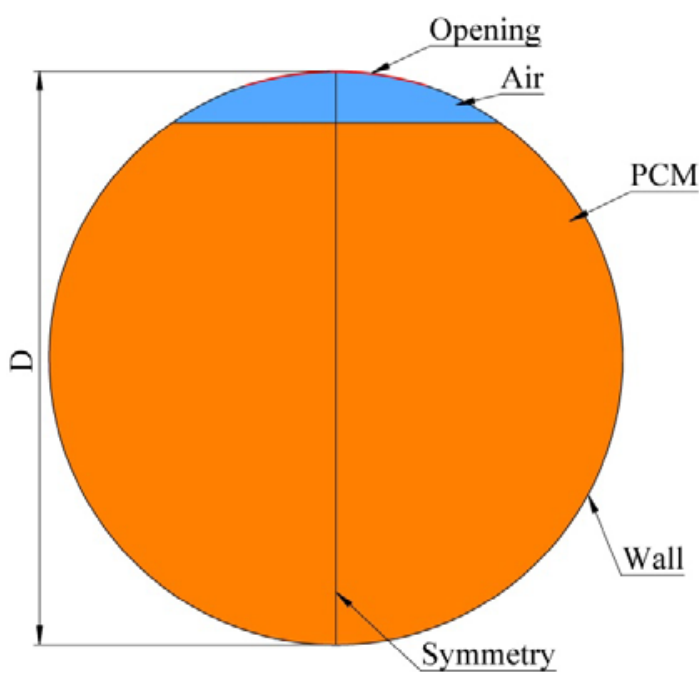

Figure 1. Geometry analyzed.

In the simulations, the diameters $(D)$ of 10,20 , 30 and $40 \mathrm{~mm}$ were analyzed. The PCM contained in the spheres is erythritol, whose phase change temperature is $391 \mathrm{~K}\left(118^{\circ} \mathrm{C}\right)$. The properties of the 
material are shown in Table 1 . The viscosity values were obtained from the experimental study of Sillick and Gregson (2012), while the other properties were obtained from Agyenim et al. (2010b) and Hesaraki (2011).

Table 1. Physical properties of erythritol.

\begin{tabular}{c|c}
\hline Property & Value \\
\hline Latent heat $(L-\mathrm{J} / \mathrm{kg})$ & 339000 \\
\hline Density $\left(\rho-\mathrm{kg} / \mathrm{m}^{3}\right)$ & $1480(389 \mathrm{~K})$ \\
& $1300(413 \mathrm{~K})$ \\
\hline Specific heat $\left(C_{p}-\mathrm{J} / \mathrm{kg} \mathrm{K}\right)$ & $1350(389 \mathrm{~K})$ \\
& $2740(413 \mathrm{~K})$ \\
\hline Thermal conductivity & $0.733(389 \mathrm{~K})$ \\
$(k-\mathrm{W} / \mathrm{m} \mathrm{K})$ & $0.326(413 \mathrm{~K})$ \\
\hline Dynamic viscosity & $2.7749 \times 10^{-5} \mathrm{~T}^{2}-$ \\
$(\mu-\mathrm{kg} / \mathrm{m} \mathrm{s})$ & $0.0231747 \mathrm{~T}+4.844$ \\
\hline
\end{tabular}

For all the cases analyzed, air that enters the sphere had temperature equal to wall temperature and atmospheric pressure, with the following density variation: $\rho=1.2 \times 10^{-5} \mathrm{~T}^{2}-0.001134 \mathrm{~T}+3.4978$ (Assis et al., 2007), where $\rho$ is the density, $\mathrm{kg} / \mathrm{m}^{3}$ and $T$ is the temperature, $\mathrm{K}$.

\section{Mathematical model}

The mathematical model used in the present work consists of the solution of the mass, momentum and energy conservation equations (ANSYS, 2015).

$$
\begin{gathered}
\frac{\partial \rho}{\partial t}+\nabla(\rho \vec{V})=0 \\
\frac{\partial \rho \vec{V}}{\partial t}+\nabla(\rho \vec{V} \vec{V})=-\nabla p+\nabla(\mu \nabla \vec{V})+\rho g+S \\
\frac{\partial(\rho h)}{\partial t}+\nabla(\rho \vec{V} h)=\nabla(k \nabla T)
\end{gathered}
$$

Equations (1), (2) and (3), represent the mass, momentum and energy conservation equations, respectively. In these equations, $t$ is the time, $s ; \vec{V}$ is the velocity vector, $\mathrm{m} / \mathrm{s} ; p$ is the pressure, $\mathrm{Pa} ; \mu$ is the dynamic viscosity, $\mathrm{kg} / \mathrm{m} \mathrm{s} ; g$ is the gravity acceleration, $9.81 \mathrm{~m} / \mathrm{s}^{2} ; S$ is the momentum source term, $\mathrm{Pa} / \mathrm{m}$; and $h$ is the total enthalpy, $\mathrm{J} / \mathrm{kg}$, obtained by the sum of the sensible enthalpy $\left(h_{s e}\right)$ and the latent enthalpy $\left(h_{l a}\right)$.

$$
\begin{gathered}
h_{s e}=h_{r e f}+\int_{T_{r e f}}^{T} C_{p} d T \\
h_{l a}=\beta L
\end{gathered}
$$

The sensible enthalpy is calculated by Eq. (4), where $h_{r e f}$ is the enthalpy at the reference temperature
$\left(T_{r e f}\right)$. The latent enthalpy is calculated by Eq. (5).

The enthalpy-porosity technique (Brent and Voller, 1988) models the interface region between solid and liquid (partly solidified region) as a porous zone.

$$
S=\frac{(1-\beta)^{2}}{\left(\beta^{3}+\varepsilon\right)} C \vec{V}
$$

The porosity in each cell is defined as equal to the liquid fraction in that cell and is calculated by the momentum source term, defined by Eq. (6). In this equation, $\varepsilon$ is a small value $(0.001)$ to avoid division by 0 (zero) and $C$ is the mushy zone constant, $\mathrm{kg} / \mathrm{m}^{3}$ $\mathrm{s}$, that indicates the damping of the velocity until it reaches zero as the material solidifies.

$$
\beta=\left\{\begin{array}{ccc}
0 & \text { if } & T<T_{s} \\
1 & \text { if } & T>T_{l} \\
\frac{T-T_{s}}{T_{l}-T_{s}} & \text { if } & T_{s}<T<T_{l}
\end{array}\right\}
$$

The PCM liquid fraction during the phase change is calculated by Eq. (7), where $T_{s}$ is the solidus temperature and $T_{l}$ is the liquidus temperature.

$$
\frac{\partial \alpha_{n}}{\partial t}+\nabla\left(\alpha_{n} \vec{V}\right)=0
$$

As the problem has different unmixed fluids, the Volume of Fluid model (VOF) is used. In this model, the volume fraction of a fluid inside a cell is described by Eq. (8), where $\alpha_{n}$ is the volume fraction of the PCM in the computational cell, whose value varies from 0 for the cell without PCM to 1 for the cell filled with PCM. The cells located in the interface between the fluids have values between 0 and 1.

In all the cases analyzed, the initial temperature is $393 \mathrm{~K}$, while $T_{s}$ and $T_{l}$ of erythritol used in the model were 389 and $391 \mathrm{~K}$, respectively. In the sphere wall, the no-slip condition was used, while the opening had the Pressure-outlet condition. In order to execute the present work, an analysis was completed of the different values of the mushy zone constant $(C)$, with $10^{8}$ presenting better results and being used in all simulations.

The solution methods used were: SIMPLE for pressure-velocity coupling, PRESTO for pressure correction, Second Order Upwind for momentum and energy and Geo-Reconstruct for volume fraction correction. The under-relaxation factors used were 0.4 for pressure; 0.2 for liquid fraction; 0.8 for energy and 0.5 for density, body forces and momentum. In all simulations, the convergence criteria were $10^{-8}$ for 
energy and $10^{-5}$ for mass and velocity.

The simulations were run on computers with Intel ${ }^{\circledR}$ Core i7 processors and 64-bit operating system. The necessary simulation time varied between 140 and 280 s of processing time for each simulated second, corresponding to a minimum of $5 \mathrm{~h}$ and a maximum of 12 days of processing time.

\section{Spatial and temporal discretization tests}

Spatial and temporal discretization tests were run for $D=10 \mathrm{~mm}$ with $\Delta T=40 \mathrm{~K}$ and $D=40 \mathrm{~mm}$ with $\Delta T=20 \mathrm{~K}$. The first case was chosen because it presented the sharpest temperature gradient in the spatial distribution. The second case was chosen because represents one of the larger simulation times, testing the result stability after necessary successive calculation steps.

The results of the three rectangular meshes, with 2448, 3918 and 5942 elements were compared. Figures 2(a, b) show that the meshes were refined near the wall. Significant differences were not observed between the results of the medium mesh (3918 elements) and the most refined mesh (5942 elements). The least refined mesh (2448 elements) presented convergence problems in the case with $D=40 \mathrm{~mm}$, and was not used. Thus, the mesh used in the present work was the medium-sized one.

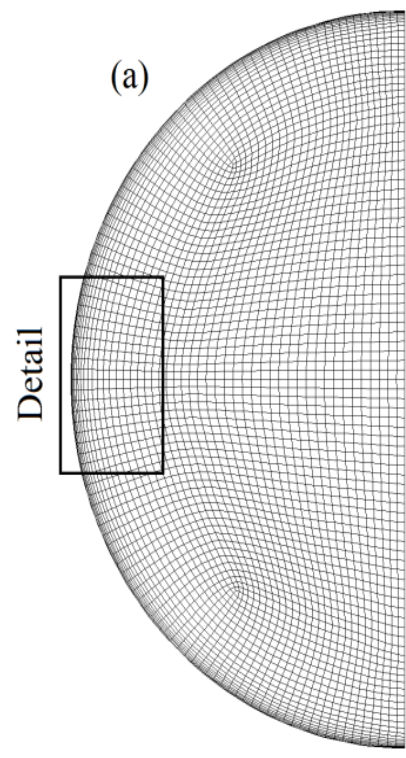

Detail

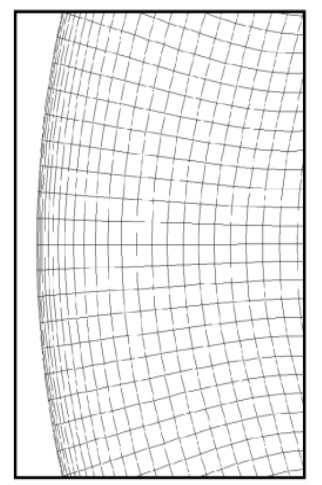

Figure 2. Computational mesh: (a) integral and (b) detail.

For the temporal discretization test, time steps (dt) of: $0.01,0.005$ and $0.002 \mathrm{~s}$ were used, with a maximum of 1000 iterations per time step. We observed sporadic convergence difficulties for the bigger $d t$. So, these were discarded. For $d t=0.005$ and $0.002 \mathrm{~s}$, the results are almost the same, thus was used $d t=0.005$, due to the unnecessary increase in processing time for $d t=0.002 \mathrm{~s}$. As the results of $\beta$ were close between the $d t$ 's, we analyzed the relative differences between the tests in order to quantify them. The larger differences were observed at the end of the process in the case with $D=40 \mathrm{~mm}$, which was near to $2 \%$ at $50 \mathrm{~min}$. However, this trend did not create problems, as it was near 0.01 , which had a small impact on the final result.

\section{RESULTS AND DISCUSSION}

The results analyzed in the present work concentrate primarily on the aspects of $\beta$ and $q$ ', as these parameters have great influence on the performance of thermal energy storage systems. Similarly, the parameter $\beta$ was also used in the numerical validation of the model used, with data from the literature.

\section{Numerical validation}

The numerical validation was performed with results of Assis et al. (2009), using RT27, in a sphere of $D=40 \mathrm{~mm}$ with $\Delta T=20 \mathrm{~K}$. Results were compared quantitatively with experimental and numerical results, while the quantitative analysis was possible only numerically, as the authors present the experimental results only in qualitative form.

In Figure 3, results of $\beta$ over time for RT27 in spheres with $D=40 \mathrm{~mm}$ and $\Delta T=20 \mathrm{~K}$ for the present work are compared with numerical results of Assis et al. (2009). From this comparison, one can observe concordance between the results across the whole process.

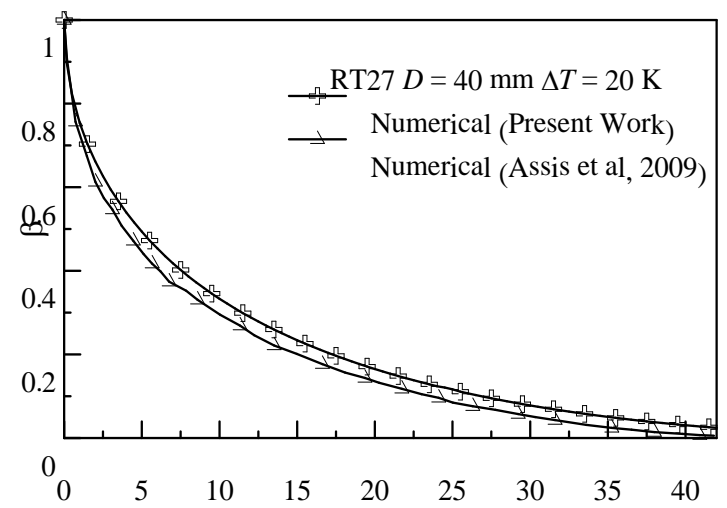

Figure 3. $\beta$ vs. time for $D=40 \mathrm{~mm}$ and $\Delta T=20 \mathrm{~K}$ with RT27, to the present work and Assis et al. (2009).

Figures 4 (a-c) present liquid fraction contours for $\mathrm{t}=5,15$ and $25 \mathrm{~min}$, of the present work, as well as experimental and numerical results of Assis et al. (2009), respectively. In these figures, it is possible to observe that the thickness of the RT27 solid layer, represented in blue, increases over time, reducing the volume occupied by the liquid, in the central region, similarly. 


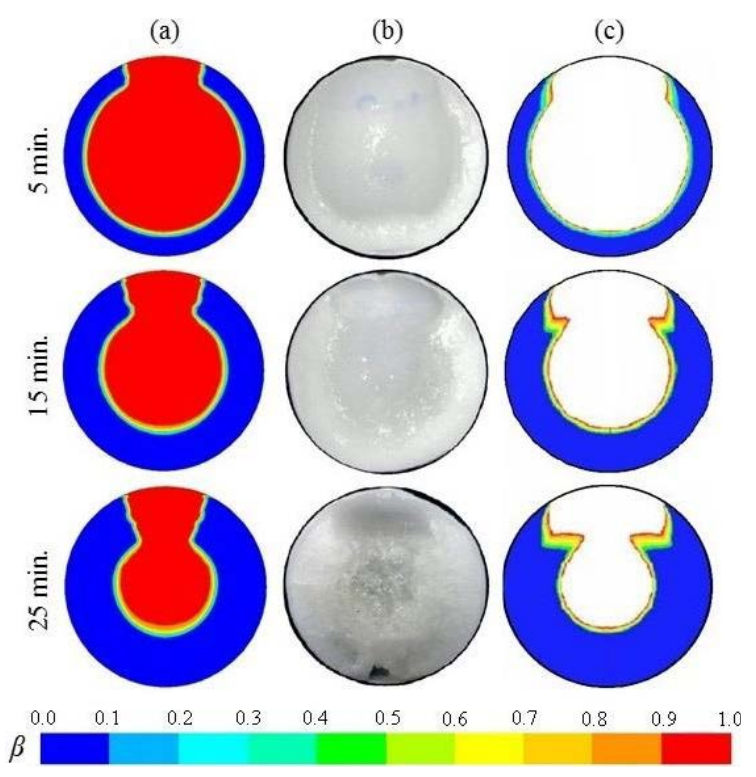

Figure 4. Contours of $\beta$ of RT27 for $D=40 \mathrm{~mm}$ and $\Delta T=20 \mathrm{~K}$, at $t=5,15$ and $25 \mathrm{~min}$ : (a) numerical, present work, (b) experimental (Assis et al., 2009) and (c) numerical (Assis et al., 2009).

It is also possible to observe good agreement of the results of the present work (Fig. 4(a)), with both experimental results (Fig. 4(b)) and with numerical results (Fig. 4(c)) of Assis et al. (2009). Although the images of experimental results have less contrast when compared to the color scale in the images of the numerical results, the similarities between the results are observable. The same color scale of Figure 3 is used in similar results throughout the present work.

\section{Liquid fraction}

The proportion of PCM in the liquid phase at a given period is represented by $\beta$, thus being proportional to the amount of energy stored. The values of $\beta$ were obtained by dividing the mass of PCM in liquid phase at a given instant by the total mass of PCM. Figures 5(a,b) show the contours of $\beta$ at the moments that $\beta$ reaches values of $0.5 ; 0.2 ; 0.05$ and 0.01 for (a) $D=20 \mathrm{~mm}$ and (b) $D=30 \mathrm{~mm}$, both with $\Delta T=20 \mathrm{~K}$. In these figures, is possible to observe the solidification process evolution, where the solid layer in blue builds up near the wall and increases gradually towards the center of the sphere, reducing thus the volume of liquid PCM, shown in red. It can be also observed that contours of $\beta$ are practically equal for a same $\beta$ value for the different $D$ shown. However, the time necessary to reach determined $\beta$ value increases proportionally in relation to the diameter. The same pattern was also observed in the other $D$ and $\Delta T$ that were analyzed.

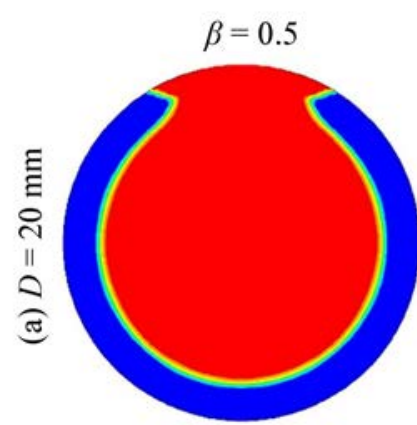

$1.17 \mathrm{~min}$

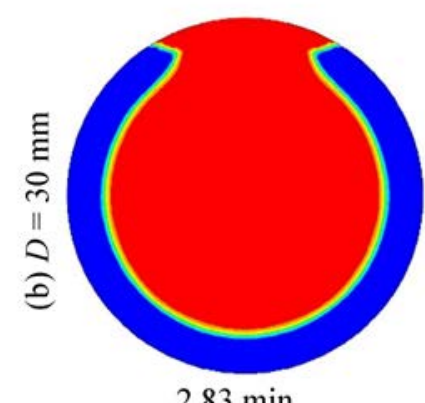

$2.83 \mathrm{~min}$

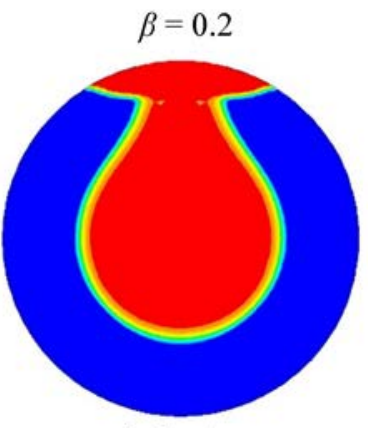

$4.67 \mathrm{~min}$

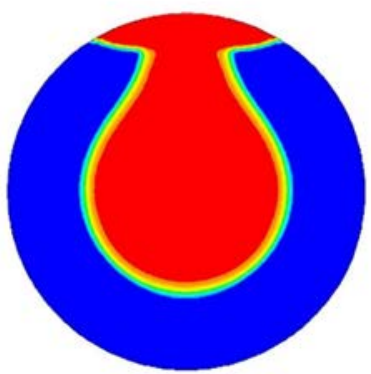

$10.33 \mathrm{~min}$

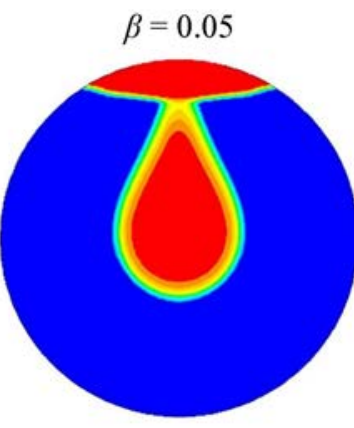

$9.5 \mathrm{~min}$

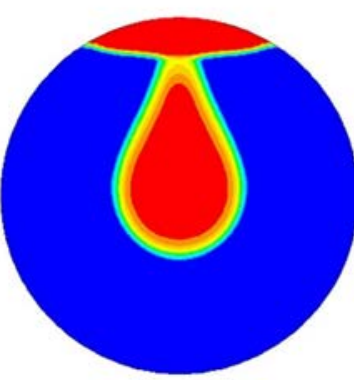

$21.0 \mathrm{~min}$

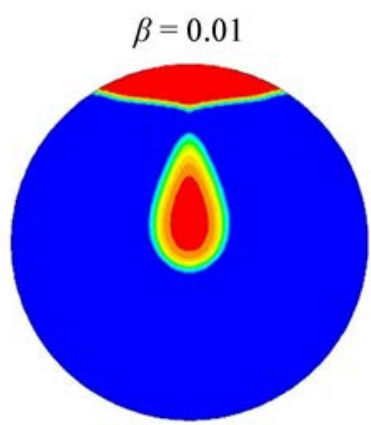

$13.0 \mathrm{~min}$

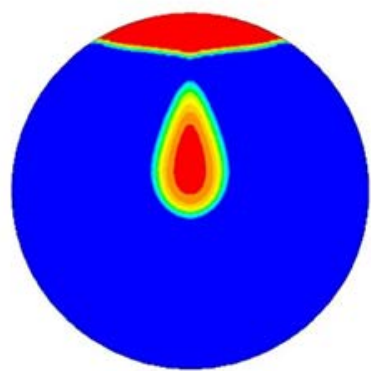

$29.67 \mathrm{~min}$

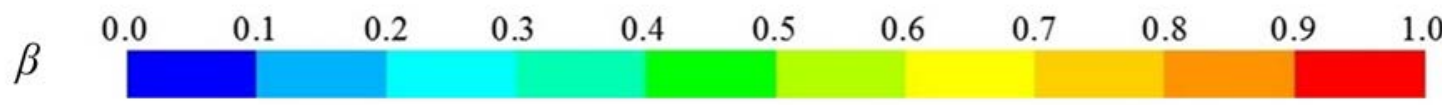

Figure 5. Contours of $\beta$ of erythritol along the solidification process with $\Delta T=20 \mathrm{~K}$, for: (a) $D=20 \mathrm{~mm}$ and (b) $D=30 \mathrm{~mm}$. 
Results of $\beta$ over time are shown in Figures 6(a,b) for (a) $D=10 \mathrm{~mm}$ and (b) $D=40 \mathrm{~mm}$, with $\Delta \mathrm{T}=10,15,20,25,30$ and $40 \mathrm{~K}$. The major feature observed is the more accentuated reduction of $\beta$ in the early stages. In these figures it is possible to observe that the curve formats, referred to each of the $\Delta T$, are very similar. One can see also that for a greater $\Delta T$, the time needed to reach complete solidification reduces. However, the total solidification time increases for bigger spheres, as shown in the case with $D=40 \mathrm{~mm}$ (Fig. 6(b)) and for the smaller $\Delta T$. Similar shapes of $\beta$ were also observed in the cases with $D=20$ and $30 \mathrm{~mm}$.
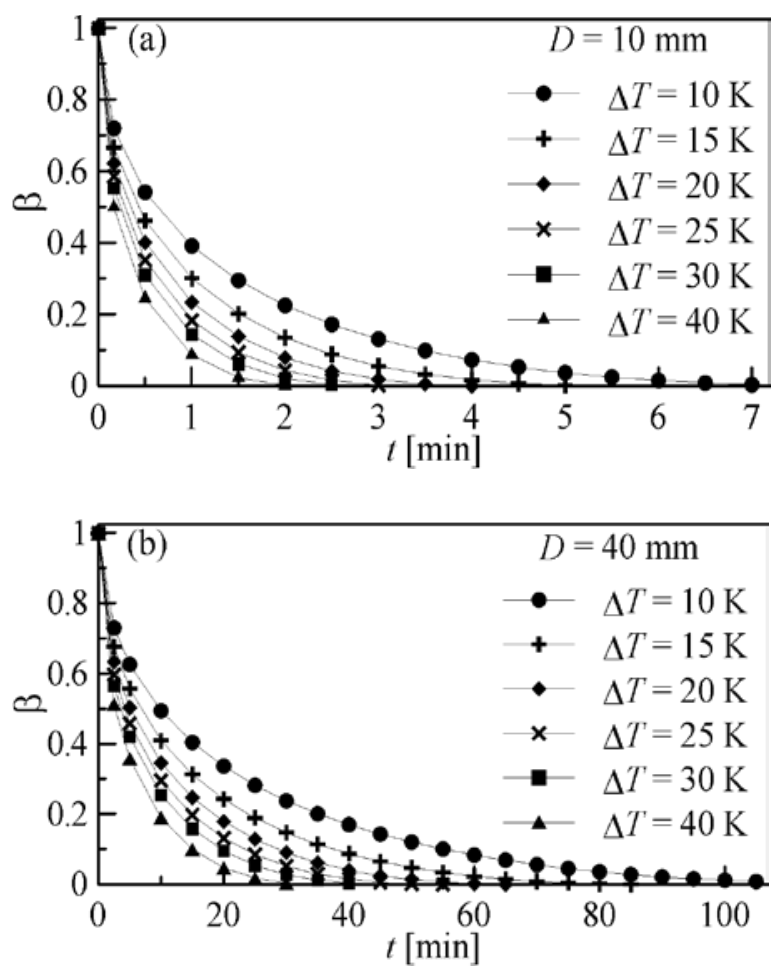

Figure 6. $\beta$ vs. time, with $\Delta T=10,15,20,25,30$ and $40 \mathrm{~K}$, for $D$ of: (a) $10 \mathrm{~mm}$ and (b) $40 \mathrm{~mm}$.

\section{Heat flux}

Results of $q$ "' over time can be seen in Figure $7(\mathrm{a}, \mathrm{b})$ for $\Delta T=10,15,20,25,30$ and $40 \mathrm{~K}$, in spheres with $D=10 \mathrm{~mm}$ and $D=40 \mathrm{~mm}$, respectively. In these figures, the high $q$ ', values in the early stages and the fast reduction in a short period stands out, with values referring to different $\Delta T$ converging to values close to each other at the end of the process. For greater $D$ this reduction is slower, in comparison to smaller spheres, as shown in Figure 7(b), with $D=40 \mathrm{~mm}$, in comparison with Figure 7(a), with $D=10 \mathrm{~mm}$. In spheres with $D=20$ and $30 \mathrm{~mm}$ similar behavior was observed. The initial values of $q$ "' for a same $\Delta T$ are similar in different $D$, as the initial thermal condition is the same for all the cases analyzed.
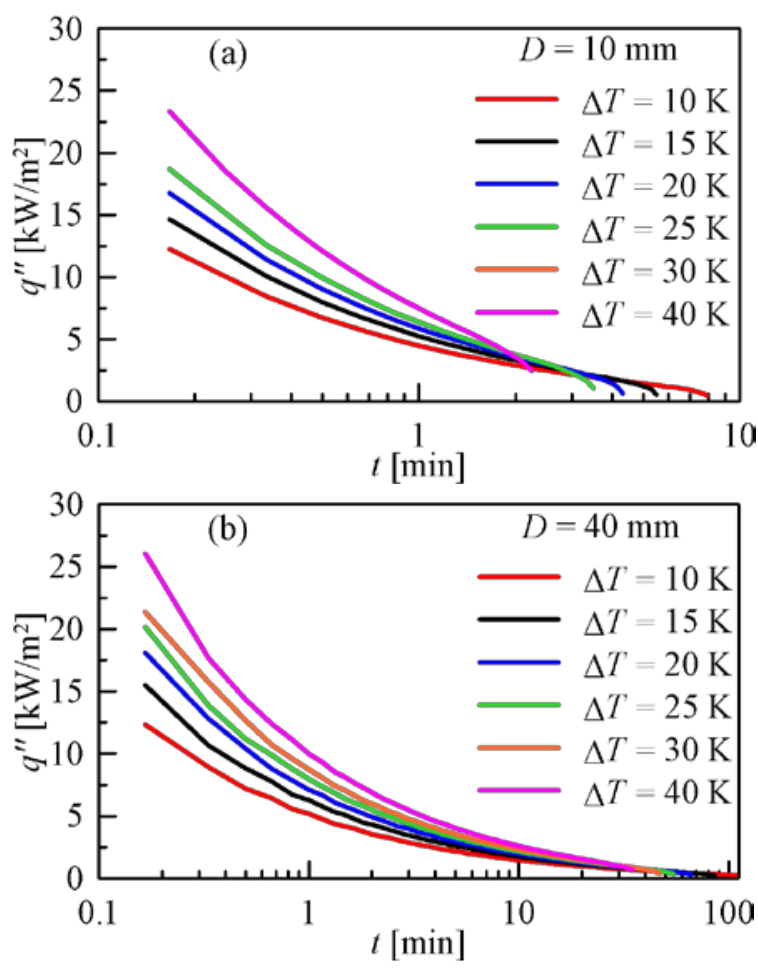

Figure 7. q"' vs. time, with $\Delta T=10,15,20,25,30$ and $40 \mathrm{~K}$, for $D$ of: (a) $10 \mathrm{~mm}$ and (b) $40 \mathrm{~mm}$.

From relating $q$ ", with $\beta$, it is possible to observe the differences between results for different sphere sizes on Figure 8, for the cases with $\Delta T=10 \mathrm{~K}$ for $D=10,20,30$ and $40 \mathrm{~mm}$. The scale of $\beta$ is shown in descending order, to make it possible to observe the curves throughout the process. It is possible to observe that $q$ "' remains higher during the solidification process for the smaller spheres, but with a shorter solidification time.

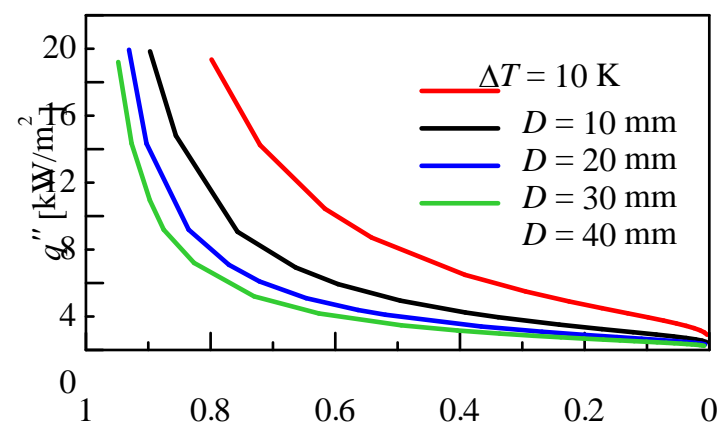

Figure 8. $q$,' vs. $\beta$ with $\Delta T=10 \mathrm{~K}$ for $D=10,20$, 30 and $40 \mathrm{~mm}$.

\section{CONCLUSIONS}

This work presented a mathematical and numerical model capable to reproduce the solidification of erythritol in spheres. The CFD analysis completed encompasses spheres with $D=10,20,30$ and $40 \mathrm{~mm}$ and $\Delta T=10,15,20,25$, 30 and $40 \mathrm{~K}$. The results of $\beta$ over time demonstrate 
that $D$ is the main factor that influences the time required to solidify the PCM, since it determines the volume and, consequently, the amount of energy stored. In relation to the $q "$, it is possible to observe a strong reduction in the initial instants, since the thermal resistance increases over time due the layer of solid PCM formed near the wall.

CFD analysis shows great value for the modeling and simulation of thermal storage systems that use PCMs, since the use of sensors in experimental analysis have influence in the process by conducting heat to the interior of the region with PCM and by interfering in the movement of the material in the liquid phase. Therefore, the main advantages observed in the analysis by CFD in this work was the precision of the results and the ease of visualization them in comparison with experimental analyzes.

\section{ACKNOWLEDGEMENTS}

The authors acknowledge the financial support of FAPERGS - Fundação de Amparo à Pesquisa do Estado do Rio Grande do Sul, CAPES - Coordenação de Aperfeiçoamento de Pessoal de Nível Superior, and UNISINOS - Universidade do Vale do Rio dos Sinos.

\section{REFERENCES}

Agyenim, F., Eames, P., and Smyth, M., 2010a, A Review of Materials, Heat Transfer and Phase Change Problem Formulation for Latent Heat Thermal Energy Storage Systems (LHTESS), Renewable and Sustainable Energy Reviews, Vol. 14, pp. 615-628.

Agyenim, F., Eames, P., and Smyth, M., 2010b, Heat Transfer Enhancement in Medium Temperature Thermal Energy Storage System using a Multitube Heat Transfer Array, Renewable Energy, No. 35, pp. 198-207.

ANSYS, Fluent Theory Guide, 2015, Ansys Inc.

Assis, E., Katsman, L., Ziskind, G., and Letan, R., 2007, Numerical and Experimental Study of Melting in a Spherical Shell, International Journal of Heat and Mass Transfer, No. 50, pp. 1790-1804.

Assis, E., Ziskind, G., and Letan, R., 2009, Numerical and Experimental Study of Solidification in a Spherical Shell, Journal of Heat Transfer, Vol. 131.

Borahel, R. S., Raymundo Junior, J., and Oliveski, R. D. C., 2015, Análise Bidimensional do Processo de Fusão de um Material de Mudança de Fase em uma Cavidade Retangular, Scientia Plena, Vol. 11, No. 08. (in Portuguese)

Borahel, R. S., Oliveski, R. D. C., and Faistauer, F., 2015, Erythritol Solidification in a Sphere: A Numerical Study, in: 23rd ABCM International Congress of Mechanical Engineering - COBEM 2015, Rio de Janeiro, Brasil.
Brent, A. D. and Voller, V. R., 1988, EnthalpyPorosity Technique for Modeling ConvectionDiffusion Phase Change: Application to the Melting of a Pure Metal, Numerical Heat Transfer, Vol. 13, pp. 297-318.

Dubovsky, V., Assis, E., Kochavi, E., Ziskind, G., and Letan, R., 2008, Study of Solidification in Vertical Cylindrical Shells, in: 5th European Thermal-Sciences Conference, The Netherlands.

Estrázulas, J. J., 2015, Estudo Numérico da Mudança de Fase de PCMs em Cavidades Cilíndricas, Master Thesis, Universidade do Vale do Rio dos Sinos (UNISINOS), São Leopoldo, RS. (in Portuguese)

Hesaraki, A., 2011, CFD Modeling of Heat Charging Process in a Direct-contact Container for Mobilized Thermal Energy Storage, Master Thesis, Mälarden University, Sweden.

Oliveski, R. D. C., and Del Col, D., 2014, Numerical Simulation of Thermal Energy Storage with PCM, in: Eurotherm Seminar \#99: Advances in Thermal Energy Storage, Lleida, Spain.

Sharma, A., Tyagi, V. V., Chen, C. R., and Buddhi D., 2009, Review on Thermal Energy Storage with Phase Change: Materials and Applications, Renewable and Sustainable Energy Reviews, Vol. 13, pp. 318-345.

Shatikian, V., Ziskind, G., and Letan, R., 2005, Numerical Investigation of a PCM-based Heat Sink with Internal Fins, International Journal of Heat and Mass Transfer, Vol. 48, pp. 3689-3706.

Shmueli, H., Ziskind, G., and Letan, R., 2010, Melting in a Vertical Cylindrical Tube: Numerical Investigation and Comparison with Experiments, International Journal of Heat and Mass Transfer, Vol. 53, pp. 4082-4091.

Sillick M., and Gregson, C. M., 2012, Spray Chill Encapsulation of Flavors within Anhydrous Erythritol Crystals, LWT - Food Science and Technology, Vol. 48, pp. 107-113. 